\title{
Network current quality enhancement under nonlinear and unbalanced load conditions using a four-wire inverter-based active shunt filter
}

\author{
Karim Belalia ${ }^{1}$, Mohammed Khodja ${ }^{2}$, Hamid Bouzeboudja ${ }^{3}$, Azeddine Bendiabdellah ${ }^{4}$, \\ Abdelkader Mostefa ${ }^{5}$ \\ ${ }^{1,3,5}$ Department of Electrical Engineering, LDDEE Laboratory, University USTO-MB Oran, Algeria \\ ${ }^{4}$ Department of Electrical Engineering, LDED Laboratory, University USTO-MB Oran, Algeria \\ ${ }^{2}$ Department of Electrical Engineering, University Ahmed Zabana, Relizane, Algeria
}

\begin{tabular}{l} 
Article Info \\
\hline Article history: \\
Received Jan 10, 2021 \\
Revised Jul 31, 2021 \\
Accepted Aug 19, 2021 \\
\hline Keywords: \\
Parallel active filter \\
Harmonic pollution \\
pq method \\
Non-linear load \\
Neutral fault \\
Active shunt filter \\
PWM, PI regulator \\
Four-arm inverter \\
Unbalance
\end{tabular}

\begin{abstract}
The flow of a large current in the neutral conductor of a transmission system is one of the major problems caused by harmonic pollution. This current can assume excessive values and even exceed the current flowing in the phases which can be extremely dangerous both for the equipment and the safety of the personnel. Currently, the parallel or shunt active filter (SAF) or parallel active filter is considered as the most effective solution to mitigate harmonic pollution and restore a sinusoidal current waveform in electrical distribution networks. The SAF can be used to compensate for harmonic currents, as well as that of the reactive power. This paper proposes a SAF circuit based on a four-arm inverter topology. The designed SAF is shown to lead to better harmonic compensation with a reduced THD (Total Harmonic Distortion) level in the presence of nonlinear and unbalanced loads in the network. The other goal of this study is to eliminate the neutral current caused by the unbalance in the polluting loads connected to the distribution network, achieve a near-sinusoidal current waveform and protect the electric network equipment.
\end{abstract}

Copyright $\odot 2021$ Institute of Advanced Engineering and Science. All rights reserved.

\section{Corresponding Author:}

Karim Belalia,

LDDEE Laboratory

Electrical Engineering Department,

USTO-MB University,

El Mnaouar ‘BP 1505, Bir El Djir 31000 Oran, Algeria.

Email: karim.belalia@univ-usto.dz

\section{INTRODUCTION}

Nowadays, harmonics are a major power quality issue and affect most industries. They are mainly due to the widespread utilisation of non-linear loads such as electrical and electronic devices and equipment Harmonic pollution generate serious consequences for the electrical system which ultimately leads to tsignificant economic losses. While the use of static power converters has contributed significantly to improving the performance and reliability of power conversion systems and applications, their non-linear characteristics, on the other hand, are the main cause of the deterioration in the quality of electrical power. Since international energy regulations require consumers to comply with harmonic standards, the filtering of harmonic components has become today a important area of research and development both in academia and industry.

The significant advances made in the field of power electronics has led to the development of new semiconductor devices with low-cost, fast switching ability and high-power applications [1-2]. These power electronic devices are widely used in variable-speed drives, controlled and uncontrolled rectifiers, uninterruptible power supplies (UPS), computers and power system integration of renewable energy sources. Power electronic devices offer a technical and economical solution for better management of electrical energy. However, due to their nonlinear characteristics, they contribute significant power quality degradation 
causing distortion of the current and the supply voltage waveforms. A frequency analysis of these waves reveals the presence of harmonic components [3-6].

However, the control of active filters remains a challenge because it is necessary to identify the disturbances and compensate for them in real time even under variable load conditions. The proposed four-line inverter topolody can neutralize the neutral current in the case of an unbalanced non-linear load.

In the literature, several papers have addressed the issue of power quality and the attenuation of harmonics by the SAF [7-11]. A comparison between simulation and experimental results is presented in [7]. The experimental setup is a $7.5 \mathrm{kVA}$ test bench based on the dSPACE Scalexio board. In the simulation work, the current THD is attenuated from $26.88 \%$ to $2.99 \%$ at the Point of Common Coupling (PCC), whereas, for the experimental work, the THD of the current is attenuated from $26.99 \%$ to $3.43 \%$. Active filters are finding more and more applications in photovoltaic (PV) systems. In [8-11], a SAF is connected to a PV farm, and it is shown to be very effective against both harmonics and non-linear loads. In [12], the authors used active power filters to improve the quality and reliability of energy in petrochemical plants. However, to the best of our knowledge, there are none of these previous studies considered the elimination of the neutral current in the case of unbalanced and polluting loads. In [13], a control strategy based on backstepping and Lyapunov theory is applied to a two-stage four-wire SAF to regulate the voltage on the DC side is proposed. The simulation and experimental results are presented to illustrate the effectiveness of the proposed control scheme. Several advanced control methods are applied to the SAF based on a conventional inverter topology. These include adaptive filtering [14], fuzzy logic [15], artificial neural networks [16], genetic algorithms [17] and neurofuzzy approach [18]. However, these control methods lead to increased size of the equipment and require large computatation hence increased runtime of the microcontrollers.

This study focuses on the design of active filters in the case of non-linear unbalanced loads. The main objective of this contribution is to find a simple and efficient solution to the problems of nonlinear load unbalances. The paper proposed an active shunt filter based on a four-arm inverter topology. The three arms are controlled by a sine-delta PWM (Pulse Width Modulation) based on proportional-integral (PI) regulators. A new algorithm is proposed to control the fourth arm in order to eliminate the current in the neutral and ensure a protection of all the equipment in the system.

The remaining of the paper is organized as follows: The first part of Section 2 is presents the SAF configuration based on a four-wire inverter. The second part focuses on the control of the proposed neutral current neutralization algorithm. The final part of Section 2 briefly introduces the instantaneous powers pq method. Section 3 presents the design of the PI controllers for the DC bus voltage and the filter currents. The simulation results in MATLAB/Simulink and discussions are presented in Section 4. This section is divided into two main parts: the first part is concerned with the simulation of the SAF connected to a balanced pollutant load whereas the second part studies the case of non-linear load unbalance.

\section{TOPOLOGY AND CONTROL OF SAF WITH NEUTRAL CURRENT NEUTRALIZATION}

\subsection{Four-arm SAF structure}

In this topology, an inverter consisting of four arms made up of eight reversible current switches (bipolar transistors, IGBT, GTO) in antiparallel with a diode is used as illustrated in Fig. 1. The polluting load absorbs a current made up of both a fundamental component and harmonic components. The purpose of active filtering is to generate harmonic currents of the same amplitude but in phase opposition with those absorbed by the load. Thus, the current absorbed from the network will be sinusoidal. It is therefore necessary to accurately identify the harmonic currents of the polluting load. In the same way for the neutral, it is necessary to generate a current in phase opposition with an identical amplitude.

The purpose of the filter is to compensate for the harmonics, the reactive power, the current in the neutral wire and the unbalanced currents that are created by single-phase non-linear loads with three rectifiers as shown in Figure 1.

$$
\left\{\begin{array}{l}
V_{f a}=\left(S_{1}-S_{4}\right) v_{d c} \\
V_{f b}=\left(S_{2}-S_{4}\right) v_{d c} \\
V_{f c}=\left(S_{3}-S_{4}\right) v_{d c}
\end{array}\right.
$$

Where $v_{f a b c}$ are the voltages of the filter.

The current in the DC part is:

$$
i_{d c}=S_{1} i_{f a}+S_{2} i_{f b}+S_{3} i_{f c}-S_{4} i_{f n}
$$

With:

$$
\begin{aligned}
& \text { if } S_{i}=1 \text { and } S_{i+4}=0 \\
& \text { if } \quad S_{i}=0 \text { and } S_{i+4}=1
\end{aligned}
$$

Where $i$ is an integer $\left(\mathrm{i}=\left[\begin{array}{lll}1 & 2 & 3\end{array}\right]\right.$ ) 


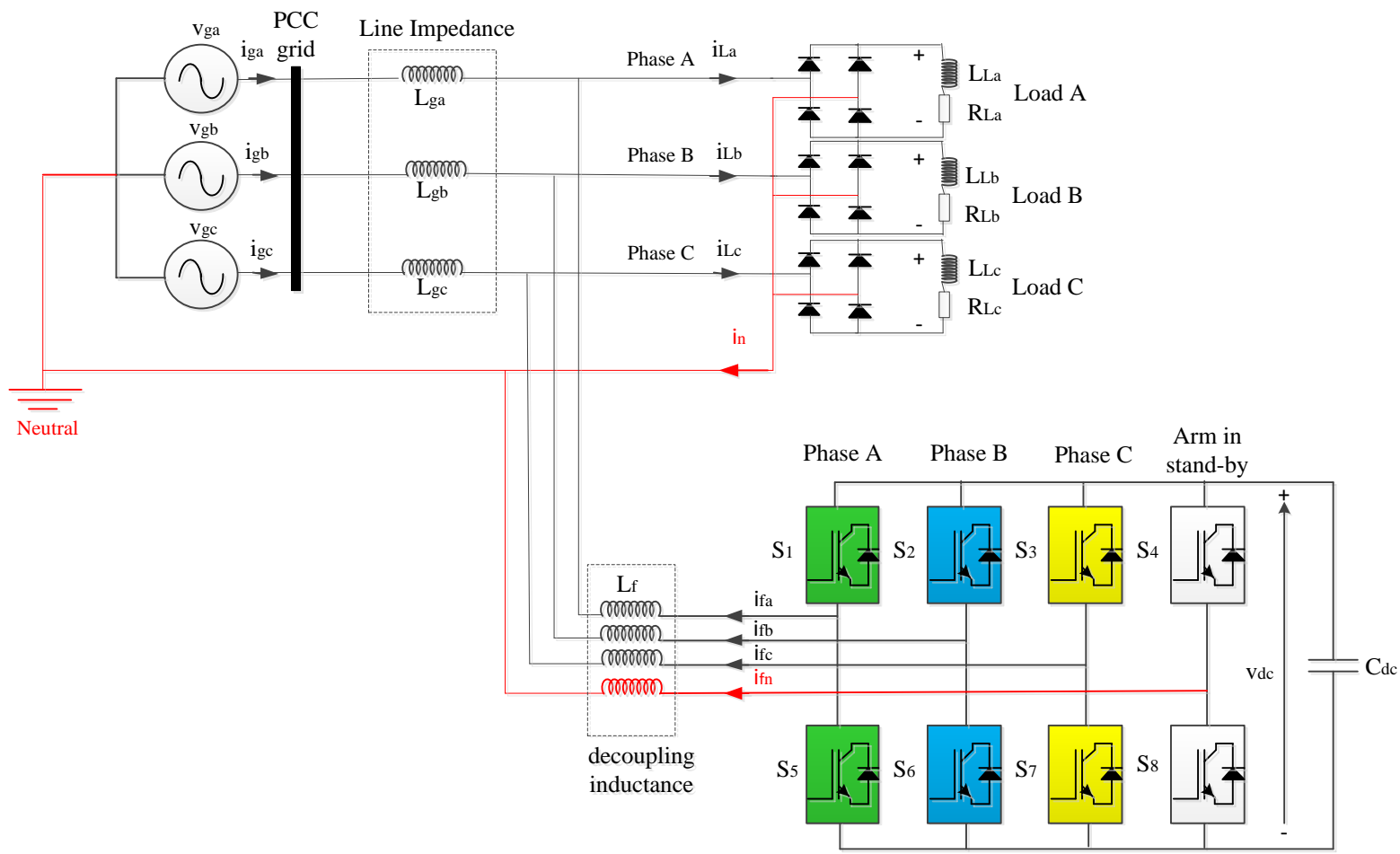

Figure 1. Four-arm SAF for a three-phase four-wire network.

\subsection{Neutral current neutralization algorithm}

The four-wire SAF topology always gives better results since the four arms of the inverter are used to control the three-phase currents of the network as well as the current in the neutral. Note that the neutral current only contains components of odd orders multiple of $3(3,9,15$, etc.), the amplitudes of which are three times greater than those of the phase currents. The three-phase balanced symmetrical non-linear loads, with connection to the neutral, generate in this conductor, harmonic currents of order 3 and harmonic currents of orders multiple of 3 . The RMS value of the neutral current can be greater than that of the current phase (up to $\sqrt{3}$ times the value of the current in a phase). To remedy the overload of the neutral conductor, the simplest solution is to choose a neutral conductor section equal to twice the section of a phase conductor. Unfortunately, this solution is expensive and does not ensure protection of the equipment. Therefore, it is proposed to integrate in this work a fourth arm to cancel the current in the neutral. Figure 2 illustrates the detail of the neutral current neutralization control block.

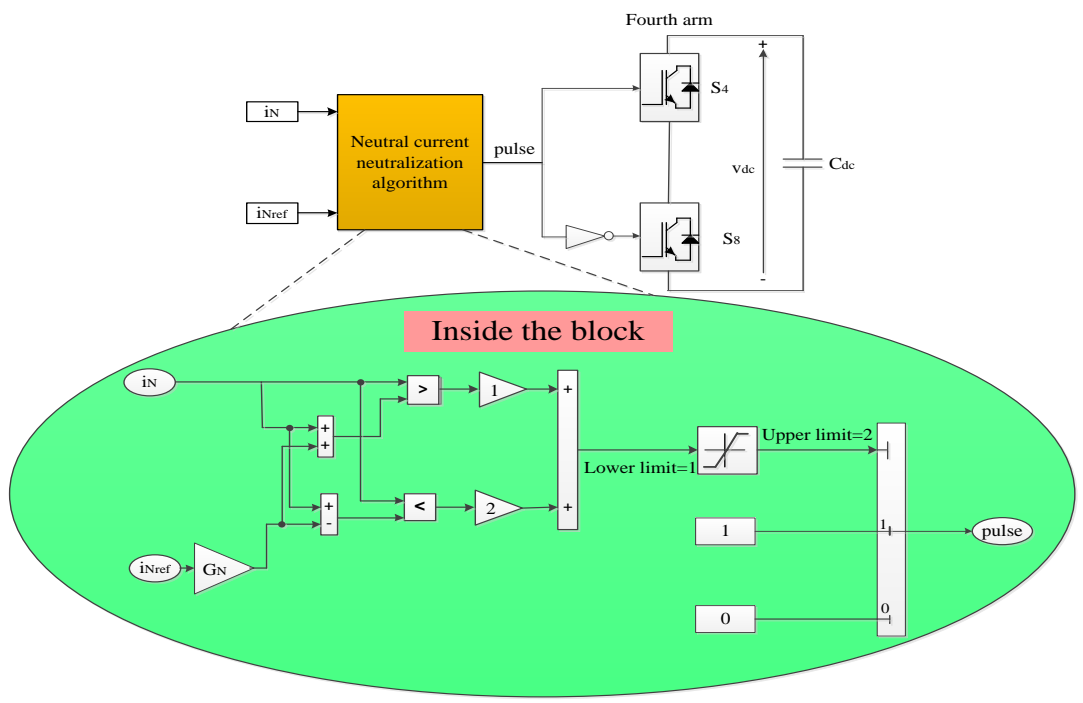

Figure 2. Neutral current neutralization control diagram. 
Table 1 shows the detailed neutral current neutralization algorithm.

Table 1. Detailed neutral current neutralization algorithm

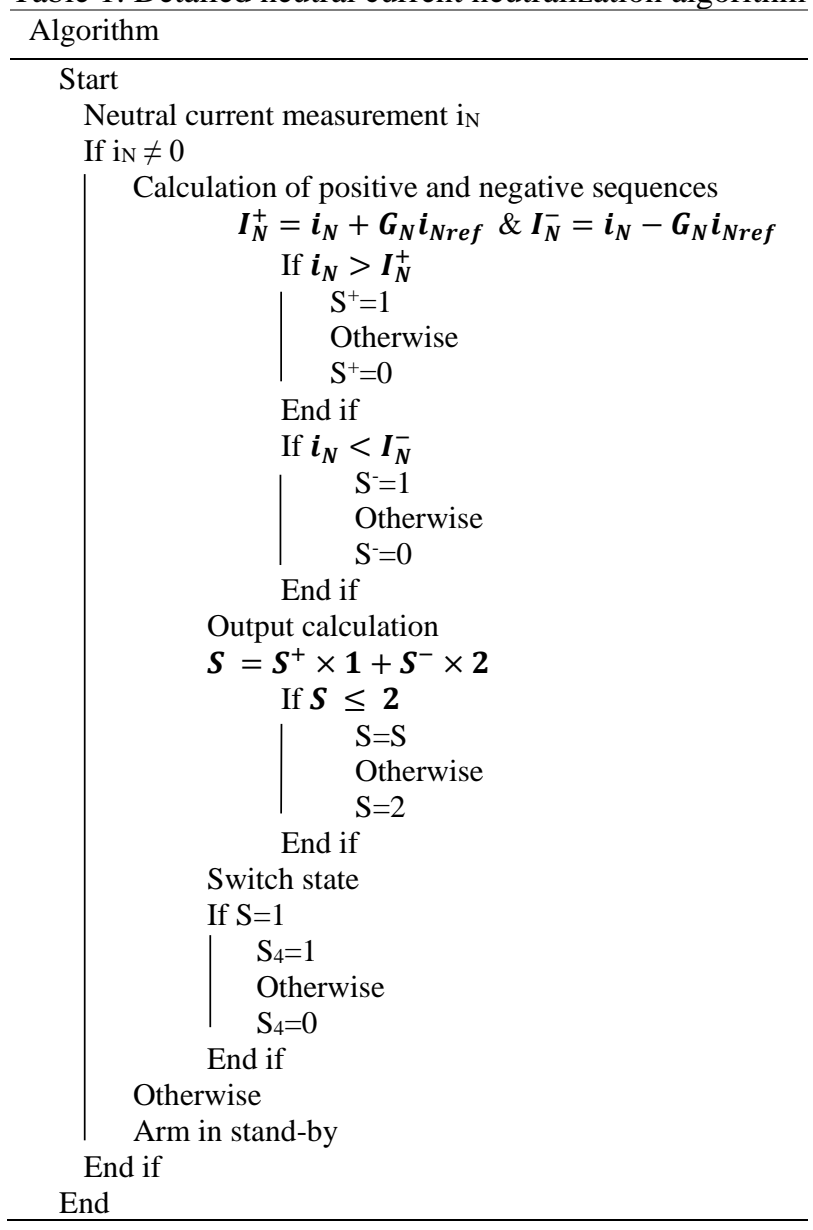

\subsection{Instantaneous power $p q$ method}

A simpler method of identifying harmonic currents consists of eliminating the DC component of the instantaneous active and reactive powers, which is relatively easy to achieve.

Let $v_{g a}, v_{g b}, v_{g c}$ and $i_{L a}, i_{L b}, I_{L c}$ be the phase-to-neutral voltages of a three-phase network (connected to a polluting load) and the three load currents respectively. This theory uses the algebraic transformation of Concordia to convert the three-phase systems of currents and voltages presented in the $X_{a b c}$ coordinate system to a new two-phase coordinate system whose axes are in quadrature Xo $\alpha \beta$ as follows: The voltage components:

The current components:

$$
\left[\begin{array}{l}
v_{g o} \\
v_{g \alpha} \\
v_{g \beta}
\end{array}\right]=\sqrt{\frac{2}{3}}\left[\begin{array}{ccc}
\frac{1}{\sqrt{2}} & \frac{1}{\sqrt{2}} & \frac{1}{\sqrt{2}} \\
1 & -\frac{1}{2} & -\frac{1}{2} \\
0 & \frac{\sqrt{3}}{2} & -\frac{\sqrt{3}}{2}
\end{array}\right]\left[\begin{array}{l}
v_{g a} \\
v_{g b} \\
v_{g c}
\end{array}\right]
$$

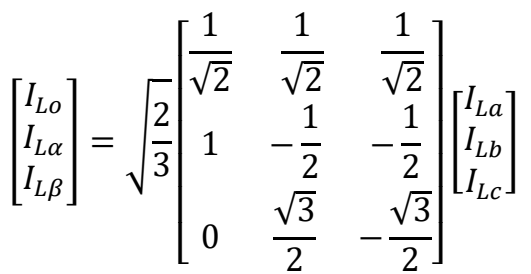


The instantaneous real and imaginary powers denoted by $p$ and $q$ respectively are defined by the following matrix relation [19]:

$$
\left[\begin{array}{l}
p \\
q
\end{array}\right]=\left[\begin{array}{cc}
v_{g \alpha} & v_{g \beta} \\
-v_{g \beta} & v_{g \alpha}
\end{array}\right]\left[\begin{array}{l}
i_{L \alpha} \\
i_{L \beta}
\end{array}\right]
$$

In the general case, each of the powers $p$ and $q$ has a DC part and a relative part, which can be expressed as:

$$
\left\{\begin{array}{c}
p=\bar{p}+\tilde{p} \\
q=\bar{q}+\tilde{q}
\end{array}\right.
$$

Where $\bar{p}$ denotes the DC power linked to the active fundamental component of the current and the voltage, $\bar{q}$ is the DC power linked to the reactive fundamental component of the current and the voltage, $\tilde{p}$ and $\tilde{q}$ represent the AC powers linked to the sum of the disturbing components of the current and the voltage.

In this paper, these components are denote by: $p_{r e f}=\tilde{p}+p_{c}$ and $q_{r e f}=q$, such that $p_{c}$ is the output of the DC bus voltage regulator.

$$
\left[\begin{array}{l}
\tilde{l}_{L \alpha} \\
\tilde{l}_{L \beta}
\end{array}\right]=\left(\left[\begin{array}{cc}
v_{g \alpha} & -v_{g \beta} \\
v_{g \beta} & v_{g \alpha}
\end{array}\right]^{-1}\left[\begin{array}{l}
\tilde{p} \\
\tilde{q}
\end{array}\right]\right)
$$

With $\Delta=v_{g \alpha}^{2}+v_{g \beta}^{2}$ is the determinant.

Let:

$$
\left\{\begin{array}{l}
\tilde{l}_{L \alpha}=\frac{v_{g \alpha}}{\Delta} \tilde{p}-\frac{v_{g \beta}}{\Delta} \tilde{q} \\
\tilde{l}_{L \beta}=\frac{v_{g \beta}}{\Delta} \tilde{p}+\frac{v_{g \alpha}}{\Delta} \tilde{q}
\end{array}\right.
$$

It can be noticed from these equations that in the expressions of $i_{\alpha}$ and $i_{\beta}$ the zero sequence power is absent [20].

$$
i_{\text {faref }}=\tilde{l}_{L \alpha}, \quad i_{f \beta r e f}=\tilde{l}_{L \beta} \quad \text { and } \quad i_{\text {foref }}=i_{o}
$$

Where $i_{o}$ is the zero-sequence component.

It should be noted that the neutral current $i_{n}$ and the zero-sequence current $i_{o}$ are linked by the relationship below:

$$
\left\{\begin{array}{l}
i_{n}=i_{L a}+i_{L b}+i_{L c} \\
i_{o}=\frac{1}{\sqrt{3}}\left(i_{L a}+i_{L b}+i_{L c}\right)=\frac{1}{\sqrt{3}} i_{n}
\end{array}\right.
$$

To determine the reference currents ensuring the compensation of disturbances, namely: the harmonic currents, the reactive power and the line current unbalance. The $p q$ theory can be employed to calculate these currents according to the desired quality of compensation. Finally, it is easy to go back to the reference currents by the inverse transformation of Concordia:

$$
\left[\begin{array}{l}
i_{\text {faref }} \\
i_{\text {fbref }} \\
i_{\text {fcref }}
\end{array}\right]=\sqrt{\frac{2}{3}}\left[\begin{array}{ccc}
1 & 0 & \frac{1}{\sqrt{2}} \\
-\frac{1}{2} & \frac{\sqrt{3}}{2} & \frac{1}{\sqrt{2}} \\
-\frac{1}{2} & -\frac{\sqrt{3}}{2} & \frac{1}{\sqrt{2}}
\end{array}\right]\left[\begin{array}{l}
i_{\text {faref }} \\
i_{\text {frref }} \\
i_{\text {foref }}
\end{array}\right]
$$




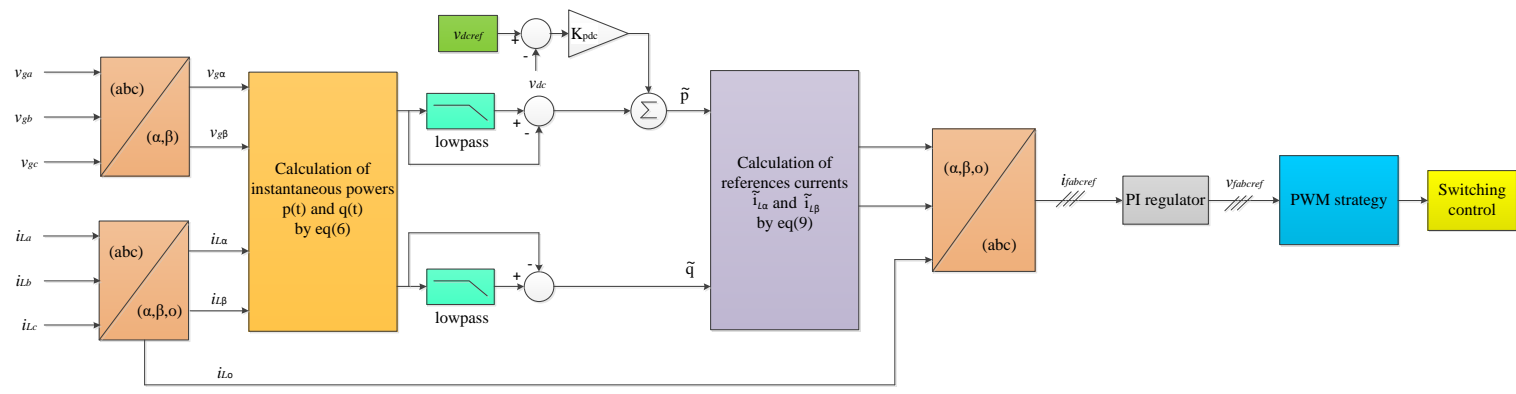

Figure 3. Identification by the instantaneous power method.

The general idea is to introduce in the forward path, upstream a proportional regulator $\left(K_{p d c}\right)$, which serves to keep the DC bus voltage of the capacitor constant and forces the filter current to follow the reference current generated by the controls. The currents regulation consists of the currents control from the network (indirect control of the $i_{g a b c}$ network). The instantaneous power method is applicable only if the network voltage is perfectly sinusoidal and balanced. The first step is to bring the network voltage $v_{g a b c}$ and the load currents $i_{\text {Labc }}$ into the Concordia reference. This transformation makes it possible to switch from a three-phase system to a two-phase system, which simplifies the mathematical expressions.

\section{DESIGN THE DC VOLTAGE AND ACTIF FILTER CURRENT REGULATORS}

\subsection{DC voltage regulation}

For small and medium powers, the most suitable energy storage element is a capacitor placed on the DC side of the inverter. The DC voltage is not constant because it depends on the active power exchanges between the polluting load and the network as well as the losses in the power components, hence the need to maintain this voltage at a constant level.

A simple proportional type regulator can be inserted. The output of the regulator $P_{c}$ is added to the disturbing active power $\tilde{p}$ and gives rise to an active fundamental current thus correcting $V_{d c}$.

The power $P_{c}$ represents the active power necessary to maintain the voltage $V_{d c}$ equal to the value of the desired reference voltage $\left(V_{\left(d c_{r e f}\right)}\right)$. The regulator used here is a simple proportional $K_{p d c}$ regulator associated with a first order low-pass filter with gain $k_{c}$ and a time constant $\tau_{c}$ [21]:

$$
K_{p d c}(s)=\frac{k_{c}}{1+\tau_{c} \cdot s}
$$

By neglecting the switching losses in the inverter as well as those in the coupling inductors, the relationship between the power absorbed by the active filter and the voltage across the capacitor becomes:

$$
P_{c}=\frac{d}{d t}\left(\frac{1}{2} C_{d c} V_{d c}^{2}\right)
$$

For small variations in the voltage $V_{d c}$ around its reference $V_{\left(d c_{r e f}\right)}$, equation (13) can be linearized as follows:

$$
P_{c}=C_{d c} \cdot V_{d c_{\text {réf }}} \frac{d}{d t}\left(V_{d c}\right)
$$

By applying the Laplace transformation to this relation, one gets:

$$
V_{d c}(s)=\frac{P_{c}(s)}{V_{d c_{-} r e f} \cdot C_{d c} \cdot s}
$$

From relation (15), and taking into account the proportional regulator. The choice of parameters, $k_{c}, \tau_{c}$ aims to obtain a minimum response time so as not to harm the dynamics of the active filter.

$$
\omega_{c}=\sqrt{\frac{k_{c}}{C_{d c} \cdot V_{d c_{-} r e f} \cdot \tau_{c}}}
$$




$$
\xi=\frac{1}{2} \sqrt{\frac{C_{d c} \cdot V_{d c_{-} r e f}}{k_{c} \cdot \tau_{c}}}
$$

The response is stable for all values of $k_{c}$, nevertheless the product $\left(k_{c} \cdot \tau_{c}\right)$ is chosen to achieve a satisfactory damping.

\subsection{Active filter current regulation}

By neglecting the resistance of the inductance $L_{f}$, the equation connecting the voltage, which must be supplied by the inverter, in order to create harmonic currents in phase opposition to those existing on the network and the voltage at the connection point is defined by:

$$
v_{f}=v_{g}+L_{f} \frac{d i_{f}}{d t}
$$

The difference between the reference current and the current measured is obtained from the following relation:

$$
\Delta i_{f}=i_{f_{-} r e f}-i_{f}
$$

From equations (18) and (19), one obtains:

$$
L_{f} \frac{d \Delta i_{f}}{d t}=\left(v_{g}+L_{f} \frac{d i_{f_{-} r e f}}{d t}\right)-v_{f}
$$

The first term on the right-hand side of equation (20) can be defined as the reference voltage $v_{f \_r e f}$, which gives the following expression:

$$
v_{f_{-} r e f}=v_{s}+L_{f} \frac{d i_{f_{-} r e f}}{d t}
$$

From equations (20) and (21), the difference between $v_{f_{-} r e f}$ and $v_{f}$, generates a current error. The voltage $v_{f_{\text {_ref }}}$ given by relation (18) is composed of two terms at different frequencies. The first term is the network voltage, which is easily measured. The second term is equal to the voltage drop across the inductance $L_{f}$ when a current crosses it equal to that of the reference. A current regulator must generate this term. The reference current is made up of harmonic currents with frequencies multiple of that of the network. To avoid harmonics due to interruptions in the operation of the regulator, a first order low pass filter can be added before this one. The control voltage becomes:

$$
V_{f}(s)=V_{g}(s)+L_{f} i_{f} s
$$

The relation (21) gives the controlled quantity $I_{f}$ as a function of the control quantity $v_{f}$. One obtains:

$$
I_{f}(s)=\frac{V(s)-V_{g}(s)}{s \cdot L_{f}}
$$
relation:

In this diagram, $G(s)$ represents the PWM controlled inverter, which can be modeled by the following

$$
G(s)=\frac{V_{d c}}{2 \cdot V_{p}}
$$

Where $V_{d c}$ is the DC side voltage of the inverter and $V_{p}$ represents the amplitude of the triangular carrier.

Generally, the most widely used regulator is the proportional integral (PI) regulator. Indeed, it is one of the simplest to implement. The control loop of the current $I_{f}$ can then be simplified as shown in Figure 4 .

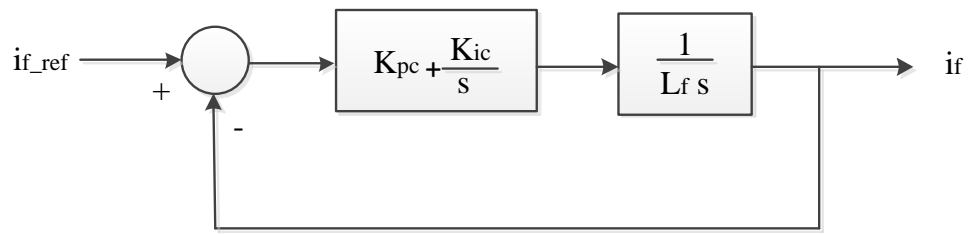

Figure 4. Simplified diagram of the filter current regulation. 


\section{RESULTS AND DISCUSSION}

The simulation model illustrates the method of identifying instantaneous powers for the detection of reference harmonic currents. It includes a proportional regulator for the regulation of the DC voltage at the terminals of the conductor and a PI regulator for the PWM control. The cut-off frequency of the second order low pass extraction filter is $50 \mathrm{~Hz}$. In addition, an algorithm for the elimination of the neutral current in order to remedy the problem of unbalance of the polluting load is used. The simulation scenarios are split into two main cases: (i) balanced load case, (ii) unbalanced load case.

\subsection{Balanced load case}

A. Inductive load $(L=0.07 H, R=4 \Omega)$

Figure 5 depicts the three-phase currents of the network, the load and the filter. The simulation results obtained show the compensation of harmonic currents by using the instantaneous power $p q$ method as a method of identifying the harmonic currents that must be injected by the filter in order to improve the THD of the network current. Note that after switching on the filter at time $t=0.1 \mathrm{~s}$, the current becomes almost sinusoidal at the PCC.

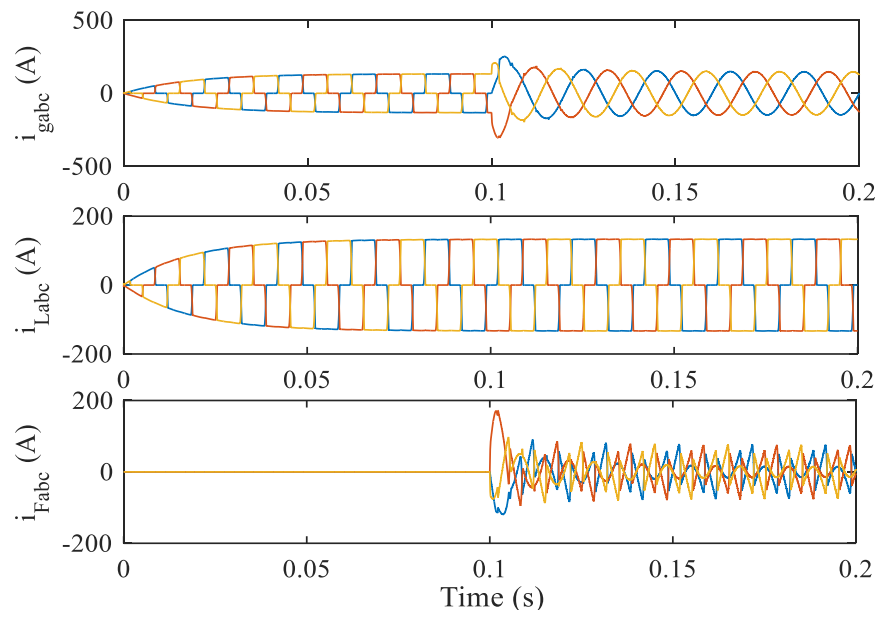

Figure 5. Three-phase current waveforms for the network, load and the filter (Inductive load).

The three-phase voltages as well as the DC voltage are shown in Figure 6. The DC bus voltage at the input of the $V_{d c}$ inverter is well regulated at its reference value $V_{d c r e f}$ with the presence of small ripples around its reference. The DC bus voltage is maintained perfectly at its reference.
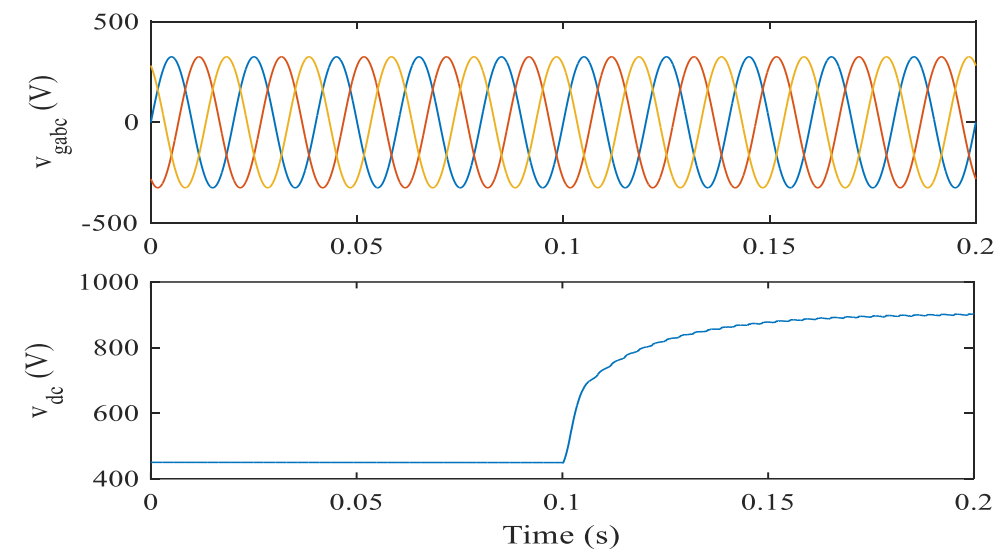

Figure 6. Three-phase network voltages and DC voltage waveforms (Inductive load).

Figure 7 depicts the current of phase A with the FFT spectrum before and after the filtering. It can be observed that before filtering (Figure $7 \mathrm{a}$ ), the THD level is equal to $27.28 \%$ for two periods of the network between the instants $0.06 \mathrm{~s}$ and $0.1 \mathrm{~s}$. The network current $I_{g a b c}$ is rich in harmonics of order $(6 \mathrm{k}+1, \mathrm{k}=$ 2.3...). After filtering (Figure $7 \mathrm{~b}$ ), the THD level is equal to $1.19 \%$ and the harmonics 5, 7, 11, 13 and 15 are all eliminated. It can be concluded that current THD is lower than the IEEE standard, which is set at $5 \%$. 

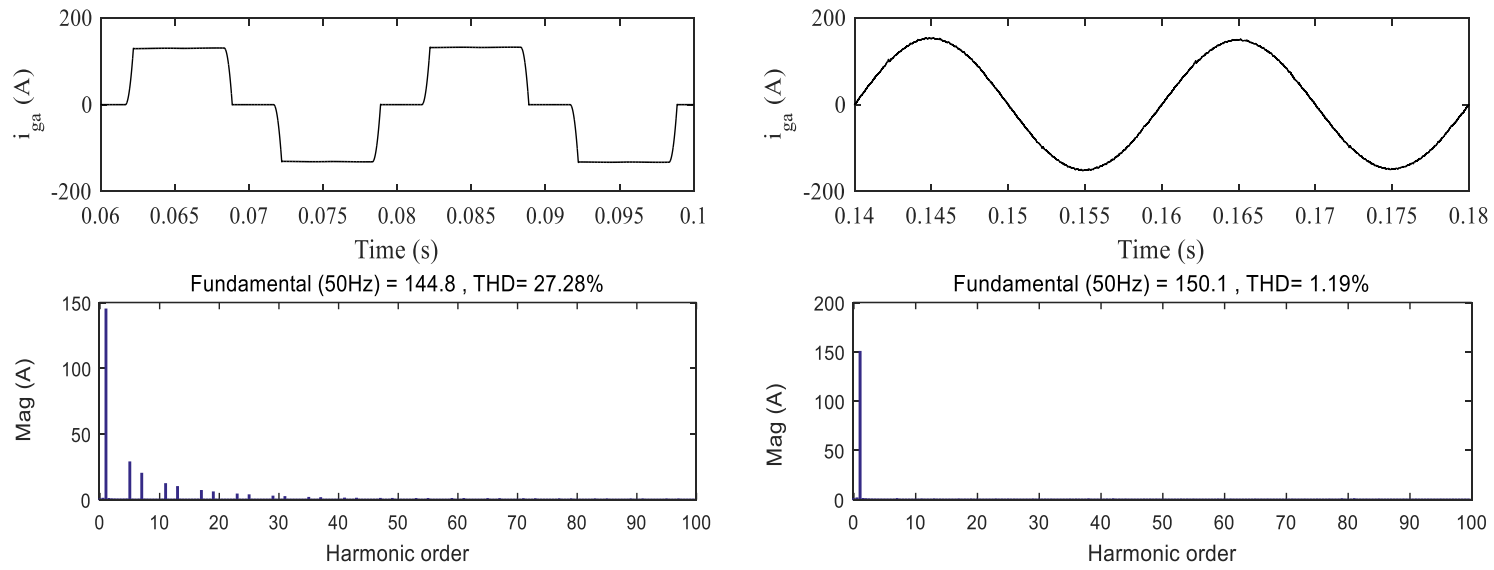

(a) Before filtering

(b) After filtering

Figure 7. Network phase A current $i_{g a}$ before and after filtering and its spectral analysis (Inductive load).

B. $R L C$ load $(R=20 \Omega, L=0.1 H, C=500 \mu F)$

This RLC load is more polluting than the inductive load. Figure 8 represents the waveforms respectively of the network, the load and the current injected from the filter. Before the filter is activated, the network current is equal to the load current. After the filter is activated at the instant $t=0.1 \mathrm{~s}$, it can be noticed that the network current becomes sinusoidal due to the use of the SAF. The current injected by the filter compensates for the harmonic currents created by the polluting RLC load.

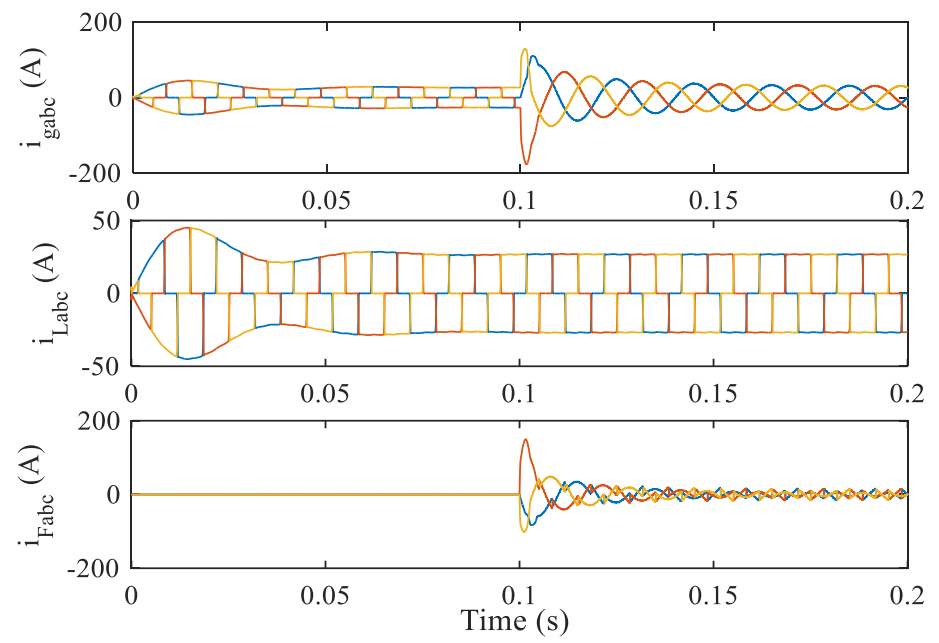

Figure 8. Three-phase current waveforms for the network, load and the filter (RLC load).
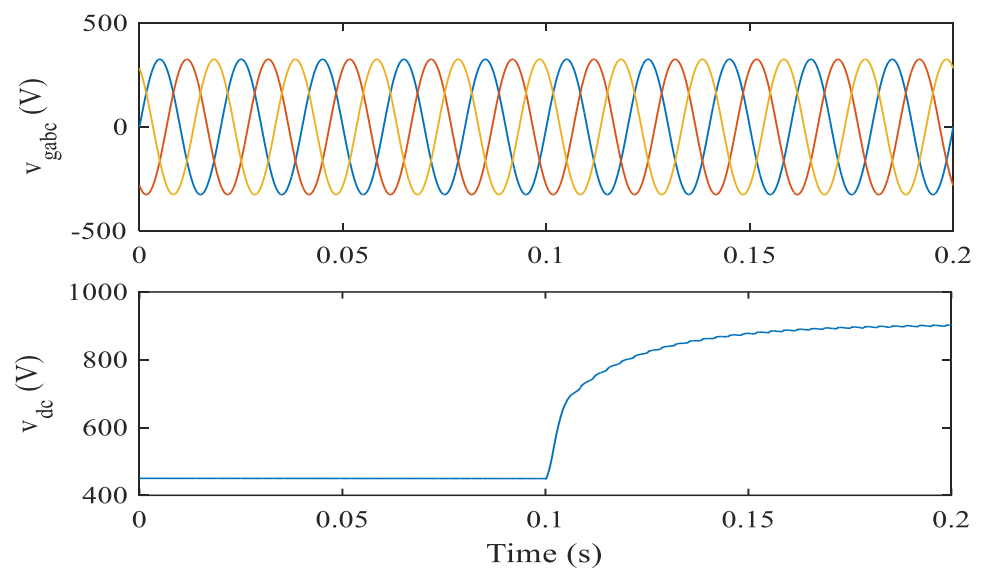

Figure 9. Three-phase network voltages and DC voltage waveforms (RLC load). 
Figure 9 shows the three-phase network voltage responses as well as the DC bus voltage. Note that the voltages are balanced with a constant frequency. The voltage across the capacitor perfectly follows its reference of $900 \mathrm{~V}$ after a short transient regime.

Figure 10 illustrates the network current with its FFT spectrum before and after connecting the filter at the PCC coupling point. Before filtering Figure 10 (a), the source current is highly distored due to harmonics with a THD of $29.42 \%$. Figure 10 (b) shows the waveform of the network current and its harmonic spectrum. It can be clearly seen that the network current after filtering is almost sinusoidal. It can be noticed that the THD is equal to $4.85 \%$, which is less than $5 \%$ (the IEEE standard).
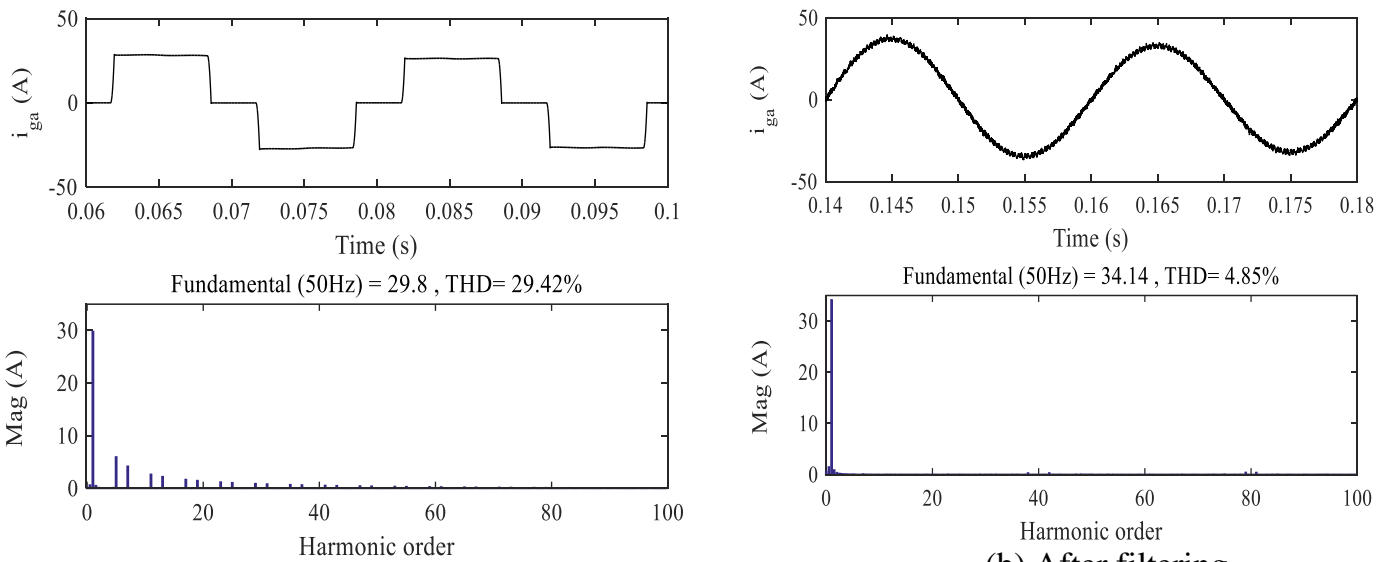

(a) Before filtering

(b) After filtering

Figure 10. Network phase A current $i_{g a}$ before and after filtering and its spectral analysis (RLC load).

\subsection{Unbalanced load case}

The single-phase inductive loads are distinguished as follows: (i) for phase A: $R_{a}=4 \Omega, L_{a}=$ $0.07 \mathrm{H}$; (ii) for phase $\mathrm{B}: R_{b}=6 \Omega$ and $L_{b}=0.04 \mathrm{H}$; (iii) finally phase C: $R_{c}=8 \Omega$ and $L_{c}=0.06 \mathrm{H}$. Figure 11 shows the waveforms of the three-phase currents of the network, the load, the filter and the neutral for the unbalanced inductive loads. It can be observed that the current is unbalanced before the application of the neutral current neutralization algorithm. Despite the use of the active filter at the instant $t=0.1 \mathrm{~s}$, the network current does not become sinusoidal and this is due to the unbalance between the non-linear loads. This unbalance is well visualized in the neutral current, which is not zero. Once the neutralization algorithm is used at the instant $t=0.2 \mathrm{~s}$, the neutral current becomes zero and consequently the network current becomes sinusoidal.
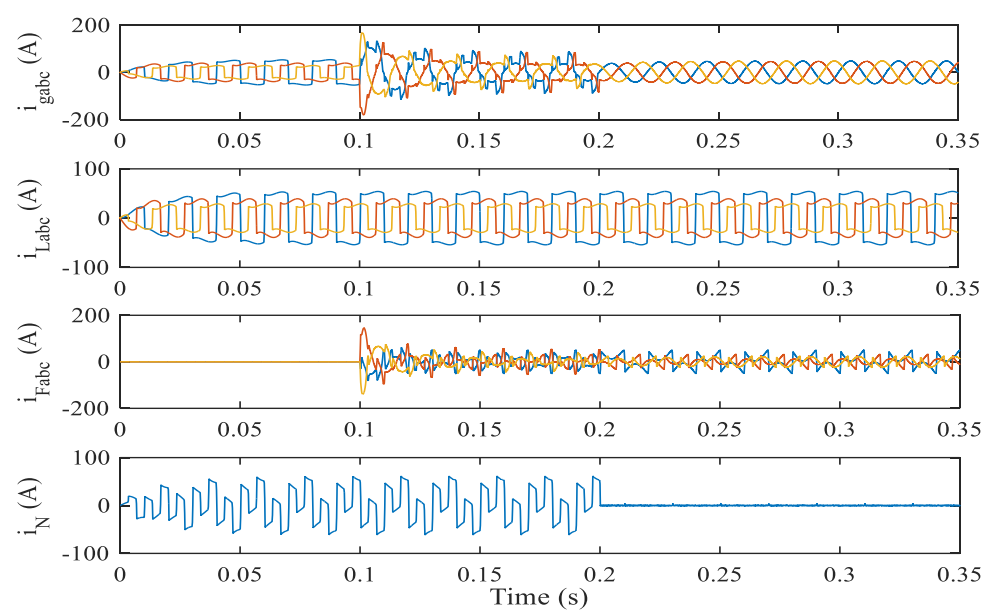

Figure 11. Currents waveforms 
The three-phase network and DC bus voltages are shown in Figure 12. The network voltages are balanced with constant frequency. The DC voltage is equal to $450 \mathrm{~V}$ before the filter is used. Once the filter is switched on, it can be noticed that the voltage does not follow its reference perfectly (there is an error due to the unbalance). By applying the fourth arm of the inverter controlled by the neutral current neutralization algorithm, it can be seen that the voltage follows its reference perfectly.
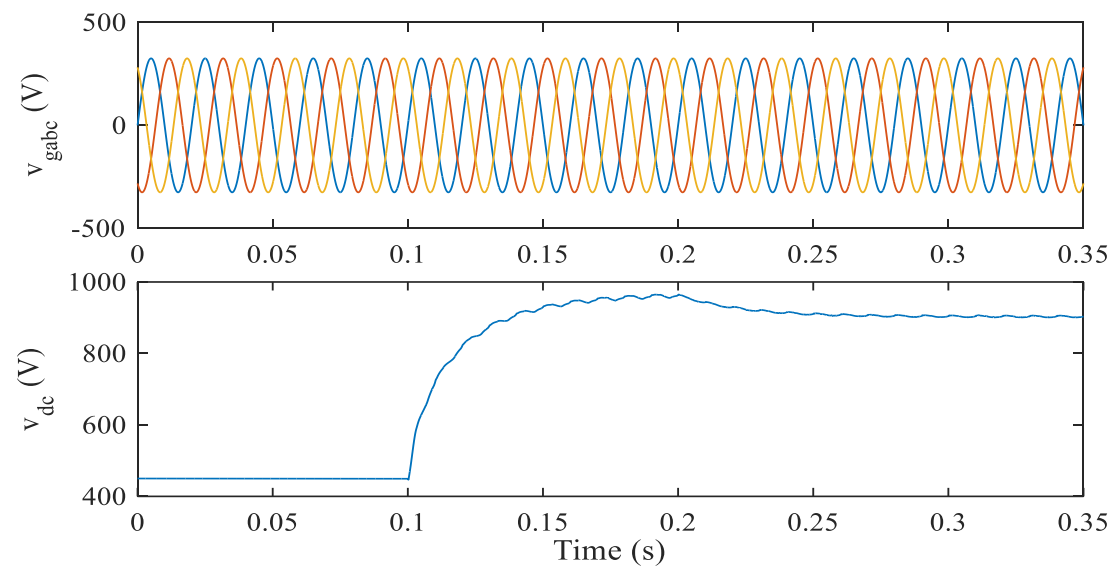

Figure 12. Three-phase network voltages and DC voltage waveforms (Unbalanced Inductive load).

Figures 13, 14 and 15 illustrate the spectral analysis respectively for phases A, B and C of the network currents. Table 2 shows the different THD values respectively for cases (a) Before filtering, (b) After filtering and (c) After using the neutral current neutralization algorithm.

Table 2. THD values obtained with the simulated inverter

\begin{tabular}{cccc}
\hline Phase & $\begin{array}{c}\text { THD [\%] } \\
\text { Before Filtering }\end{array}$ & $\begin{array}{c}\text { THD [\%] } \\
\text { After Filtering }\end{array}$ & $\begin{array}{c}\text { THD [\%] } \\
\text { Neural current neutralisation }\end{array}$ \\
\hline A & 43.97 & 48.99 & 2.43 \\
B & 44.53 & 38.91 & 2.52 \\
C & 42.49 & 38.13 & 2.43 \\
\hline
\end{tabular}

It can be seen that after using the fourth arm, the inverter corrects the THD for all the network phases and the harmonic levels become acceptable according to the IEEE standard.

The SAF based on a three-level, four-wire inverter has been studied in [22]. Two scenarios (an unbalance in the first place is carried out in Phase $\mathrm{C}$ of the network with a load $L_{c}=1 \mathrm{mH}$ and $\mathrm{Rc}=2.75 \Omega$ and then another unbalance is used in Phase $\mathrm{C}$ for an inductive load of $L_{b}=1 \mathrm{mH}$ and $R_{b}=3 \Omega$ ) are used to test the two proposed controls: the first is based on the fuzzy controller associated with self-tuning filters (STF) and the second is based on the active \& reactive powers method $\mathrm{p}-\mathrm{q}$ to compare the impact of these methods on the quality of the current. Before filtering, the THD of the current is $22.30 \%$, after using the p-q theory, the THD is reduced to $8.62 \%$ and to $1.89 \%$ with the proposed method. However, the control scheme proposed in [22] may increase the complexity of implementing this method in practice. Another study of an active fourwire shunt filter is proposed in [23]. The author proposes a CPT (Conservative Power Theory) method to compensate for non-linear load unbalances. Results by MATLAB / SIMULINK and by the Opal-RT real-time simulator were presented. After the use of the non-linear load unbalances, the THD of the current respectively for the three phases A, B and C are: $19.75 \%, 17.59 \%$ and $15.70 \%$. Before the filtering for the simulations by MATLAB the THD for three phases are: $1.74 \%, 1.84 \%$ and $1.74 \%$, and using the real-time simulator OpalRT are: $4.05 \%, 4.17 \%$ and $4.05 \%$. In order to demonstrate the superiority and performance of the proposed control strategy in this paper as compared to the advanced control method proposed in [22-23]. The results obtained in this article (the THD is approximately $44 \%$ before filtering and $2.5 \%$ after neutralization of the neutral current, see Table 2) are very satisfactory and the method used is simple to implement. 

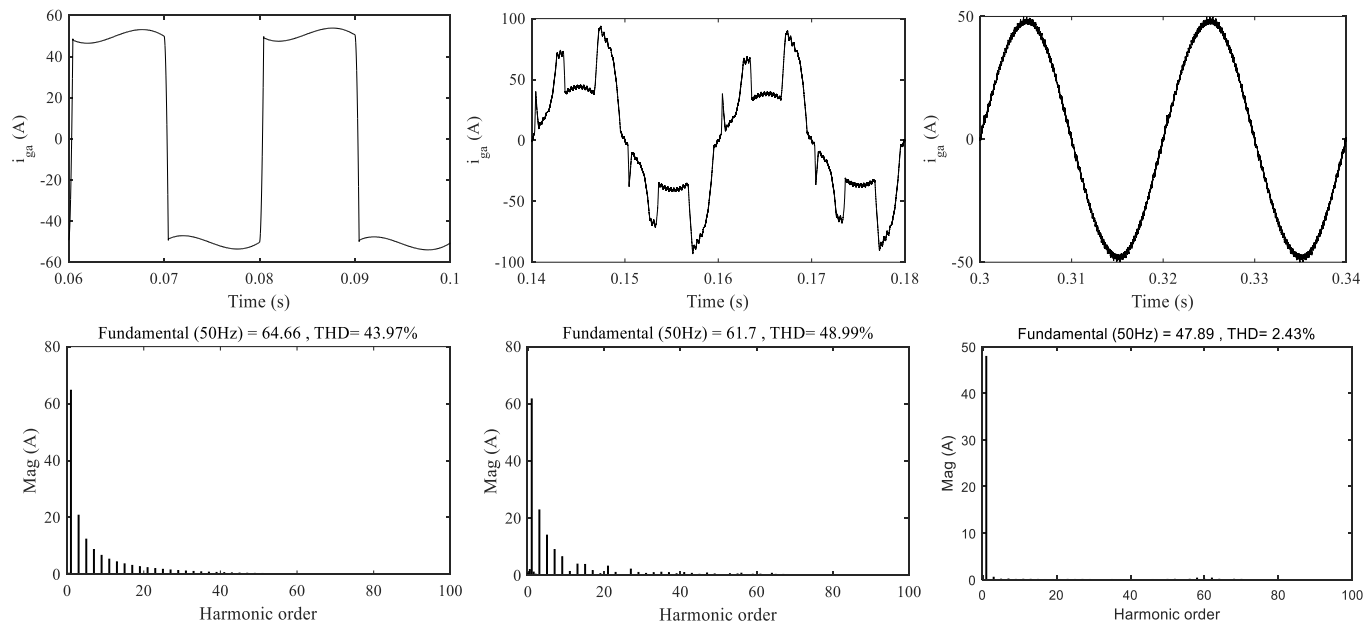

(a) Before filtering

(a) After filtering

(c) Neural current neutralisation

Figure 13. FFT analysis of phase A network current (Unbalanced Inductive load).
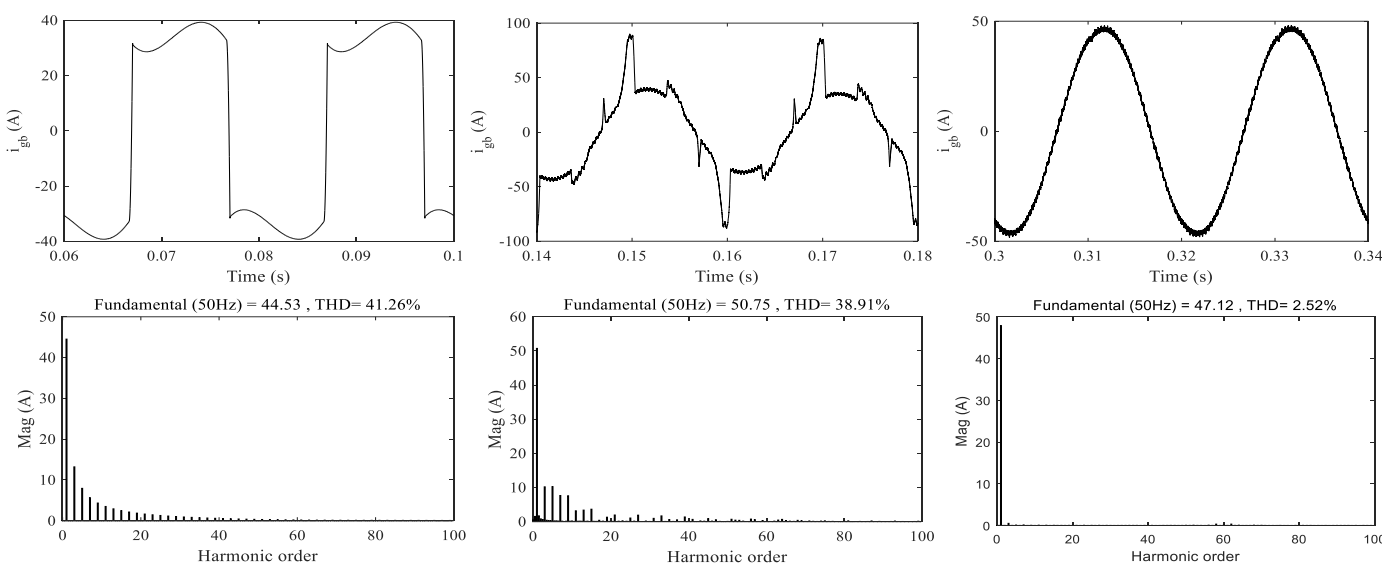

(a) Before filtering

(a) After filtering

(c) Neural current neutralisation

Figure 14. FFT analysis of phase B network current (Unbalanced Inductive load).
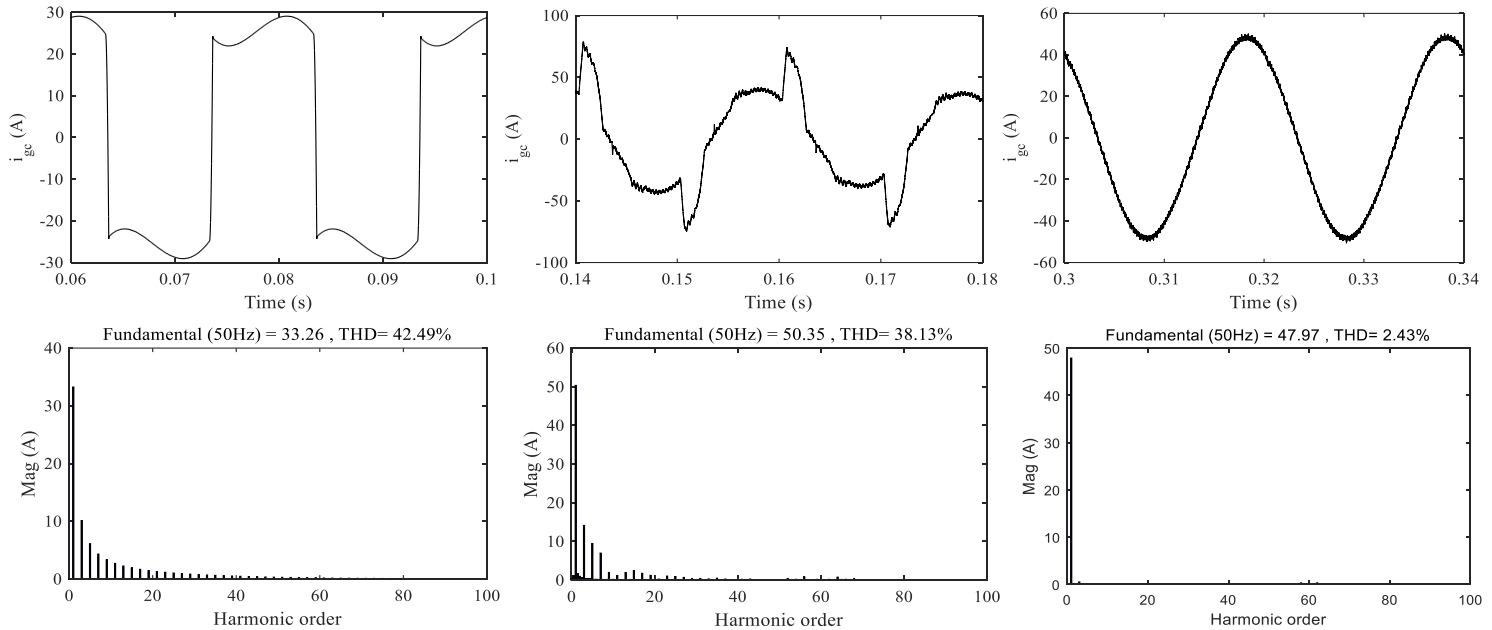

(a) Before filtering

(b) After filtering

(c) Neural current neutralisation

Figure 15. FFT analysis of phase C network current (Unbalanced Inductive load). 


\section{CONCLUSION}

This paper proposed a shunt active filter (SAF) based on a four-arm voltage source inverter topology to mitigated harmonic pollution in distribution network due to non-linear loads. The filtering process employs an appropriate control method to extract the reference current as well as the voltage regulation of the inverter DC bus capacitor. The fourth arm of the inverter is designed to neutralize the neutral current. The simulation results obtained shows good dynamics of the four-wire SAF against unbalanced non-linear loads. Finally, as perspective, the authors propose to apply the active four-wire shunt filter in a microgrid and attempt to further improve the THD using multilevel inverter topologies. Other more robust control techniques such as sliding mode of order 2 or intelligent control techniques based on fuzzy logic, neural network or neuro-fuzzy methods can also be investigated as future work.

\section{APPENDIX}

\begin{tabular}{lll}
\hline System & Designation & Values \\
\cline { 2 - 3 } & The effective voltage & $V_{s}=220 \sqrt{2} \mathrm{~V}$ \\
& The frequency & $f=50 \mathrm{HZ}$ \\
& Internal resistance & $R_{s}=0.1 \mathrm{~m} \Omega$ \\
& The internal inductance & $L_{s}=1 \mu \mathrm{H}$ \\
\hline \multirow{3}{*}{ Active parallel power filter } & Storage capacity & $C_{d c}=2.5 \mathrm{mF}$ \\
& Output filter (coupling inductance) & $L_{f}=1 \mathrm{mH}$. \\
& Reference voltage & $V_{d c \text { ref }}=900 \mathrm{~V}$ \\
\hline \multirow{3}{*}{ Control parameters of the PAF } & DC bus voltage controller & $k_{c}=100$ \\
& PI controller for reference currents & $k_{p}=300$ \\
& & $k_{i}=35$ \\
\hline \multirow{3}{*}{ Simulation conditions } & Sampling time & $T_{e}=4 \mu \mathrm{s}$ \\
& Step type & no variable \\
& Method of resolution & ode15s (stiff / NDF ) \\
\hline
\end{tabular}

\section{REFERENCES}

[1] M. A Perez, S. Bernet, J. Rodriguez, S. Kouro, and R. Lizana, "Circuit Topologies, Modeling, Control Schemes, and Applications of Modular Multilevel Converters". IEEE Transactions on Power Electronics, Vol. 30, No. 1, January 2014.

[2] J. Ananthu, V. Srikanth, "Voltage Balancing of Modular Multilevel Converter for an Induction Motor Drive ". IEEE 2017 International Conference on Intelligent Computing, Instrumentation and Control Technologies (ICICICT).

[3] A. H. Abdulwahid, "Advanced Control Method for Improving Power Quality of Microgrid Based on SVPWM Technology", IEEE 2019 the $4^{\text {th }}$ International Conference on Power and Renewable Energy.

[4] R. R Nasyrov, R. I. Aljendy, A.L Abdelaziz, A.A.Z. Diab, “Enhancement of Power Quality with Hybrid Distributed Generation and FACTS Device” IETE J. Res. 2019, 1-12.

[5] R. R. Nasyrov , R. I. Aljendy, A. A. Zaki Diab "Adaptive PI controller of active power filter for compensation of harmonics and voltage fluctuation based on particle swarm optimization (PSO)" In Proceedings of the 2018 IEEE Conference of Russian Young Researchers in Electrical and Electronic Engineering (EIConRus), Moscow, Russia, 29 January-1 February 2018; pp. 719-724.

[6] P. Jintakosonwit, H. Fujita, H. Akagi, S. Ogasawara, "Implementation and performance of cooperative control of shunt active filters for harmonic damping throughout a power distribution system”, IEEE Trans Ind Appl, vol.39, no.2, pp. 556-64, 2013.

[7] W. Rohouma, R. S. Balog, A. A. Peerzada, M. M. Begovic, "D-STATCOM for harmonic mitigation in low voltage distribution network with high penetration of nonlinear loads", Renewable Energy 145 (2020) 1449-1464.

[8] C. K. Manikanta, I. M. Kumar, D. S. Reddy, G. L. Narayana, P. Dharani, "Power quality improvement in grid connected solar system”, Journal of Critical Reviews, Vol 7, Issue 6, 2020.

[9] S. Devassy, B. Singh, "Control of a Solar Photovoltaic Integrated Universal Active Power Filter Based on a Discrete Adaptive Filter”, IEEE Transactions on Industrial Informatics, vol. 14, n. 7, pp. 3003-3012, 2018.

[10] M. Rasul, H. Khang, M. Kolhe, "Harmonic mitigation of a grid-connected photovoltaic system using shunt active filter", 20th International Conference on Electrical Machines and Systems (ICEMS 2017), Sydney Australia, August 2017.

[11] M. Bezerra, J. Oliveira, P .Praça, D. Oliveira, L. Barreto, "Proposal of a control scheme for an active filter on PV micro-inverter applications", IEEE Applied Power Electronics Conference and Exposition (APEC 2017), Tampa, FL, USA, March 2017.

[12] S. Kamala, B. Reddy, B. Sen, S. Panda; G. Amaratunga. "Improvement of power quality and reliability in the distribution system of petrochemical plants using active power filters", IEEE International Conference on Industrial Technology (ICIT 2018), Lyon, France, February 2018.

[13] A. Ben Amar, L. Zellouma, M.T. Benchouia, T. Mahni, "three-phase four-wire shunt active filter based on backstepping controller”, Rev. Roum. Sci. Techn.-Électrotechn. et Énerg, Vol. 64, 4, pp. 397-402, Bucarest, 2019 
[14] P, Garanayak. G, Panda. P.K, Ray. "Harmonic estimation using RLS algorithm and elimination with improved current control technique based SAPF in a distribution network" Int. J. Electr. Power Energy Syst. 2015, 73, 209-217.

[15] K.K, Pedapenki. S.P, Gupta. M.K, Pathak. "Comparison of PI \& fuzzy logic controller for shunt active power filter". In Proceedings of the 2013 IEEE 8th International Conference on Industrial and Information Systems, Peradeniya, Sri Lanka, 17-20 December 2013; pp. 42-47.

[16] A, Sabo. N.I, Abdul Wahab. M.A, Mohd Radzi. N.F, Mailah. "A modified artificial neural network (ANN) algorithm to control shunt active power filter (SAPF) for current harmonics reduction." In Proceedings of the 2013 IEEE Conference on Clean Energy and Technology (CEAT), Lankgkawi, Malaysia, 18-20 November 2013; pp. 348-352.

[17] W, Lenwari. M, Sumner. P, Zanchetta. "The Use of Genetic Algorithms for the Design of Resonant Compensators for Active Filters.” IEEE Trans. Ind. Electron. 2009, 56, 2852-2861.

[18] A, Benyamina. S, Moulahoum. I, Colak. R, Bayindir. "Hybrid fuzzy logic-artificial neural network controller for shunt active power filter." In Proceedings of the 2016 IEEE International Conference on Renewable Energy Research and Applications (ICRERA), Birmingham, UK, 20-23 November 2016; pp. 837-844.

[19] M. Marcu, F-G. Popescu, T. Niculescu, L. Pana, A. D. Handra, "Simulation of power active filter using instantaneous reactive power theory", 2014 16 $6^{\text {th }}$ International Conference on Harmonics and Quality of Power (ICHQP).

[20] T. D. Castillo; J. R. Castro, "Renewable Energy Source P-V conected to the grid through Shunt Active Power Filter based in P-Q theory", 2018 IEEE Third Ecuador Technical Chapters Meeting (ETCM).

[21] K. Khechiba, L. Zellouma,A. Kouzou,A. Khiter, "Comparative Analysis on Shunt Active Power Filter Based PQ Control Strategy Using HCC, SPWM and SVPWM Switching Signal Generation Techniques", 2018 15th International Multi-Conference on Systems, Signals \& Devices (SSD).wwwwr' 'a\&\&\&\&a' $\quad((($ v -| 2018 IEEE Third Ecuador Technical Chapters Meeting (ETCM).

[22] D, Djendaoui. A, Benaissa. B, Rabhi. L, Zellouma. " SELF TUNNING FILTER FOR THREE LEVELS FOUR LEGS SHUNT ACTIVE POWER FILTER WITH FUZZY LOGIC CONTROLLER", Acta Polytechnica 61(3):415-427, 2021.

[23] G, Ramalingam, A, Kumar Choudhary. S, Mikkili, "Modelling and Analysis of PV-Based Shunt Active Filter with BES and Conservative Power Theory for Enhancing Power Quality", International Journal of Emerging Electric Power Systems. 2019; 20190012

\title{
BIOGRAPHY OF AUTHORS
}

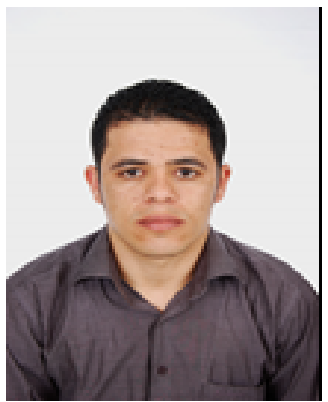

Karim BELALIA was born on January 15, 1982. He received the magister degree in Electrical Engineering from ENP-MA Oran, Algeria and Bachelor of Technology from ENSET Oran in 2016 and 2006. He is currently a PHD student in Electrical Engineering Department of USTOMB Oran, and a researcher in the LDDEE Laboratory. His areas of intrest include Hybrid renewable energy systems and Power electronics.

\footnotetext{
Hamid BOUZEBOUDJA is a Professor in Electrical Engineering Department of ENP-MA Oran. He is a researcher in the LDDEE Laboratory. His areas of interest include electrical machines, Optimization and Electrical Networks, Smart grid. He has authored several scientific papers and international communications
}

\begin{abstract}
Azeddine BENDIABDELLAH, IEEE Member. He received his Bachelor Engineering degree (Honors class) in Electrical Engineering from the University of Sheffield, England, in 1980, and his PhD degree from the same University in 1985. He is currently Professor Lecturer, Researcher and Director of the Development Electrical Drives Laboratory and responsible of the Diagnostic Group at the University of Sciences and Technology of Oran (USTO-MB), Algeria. His research interests include Electrical Machines and Drives Analysis and Modelling, Electrical Machines and Drives Control, Electrical Machines and Drives Diagnosis, Power Converter Detection Fault \& Fault Tolerance.
\end{abstract}

